\title{
Online Education \& MOOCs: Teacher Self-Disclosure in Online Education and a Mediating Role of Social Presence
}

\author{
Komal Akram Khan * $\quad$ S. M. Tariq Rafi ${ }^{\dagger}$
}

\begin{abstract}
In online education, students have been observed to face a few barriers in the overall learning and experience such as absence of physical presence of the instructor, lack of instructorstudent relationship, lack of student satisfaction and perceived learning. This research was conducted to study a few key variables in online education that may or may not have their effect on the perceived knowledge gain by students such as teacher self-disclosure, social presence and teacher-student relationship satisfaction. This study is significant because it will provide important variables to universities offering online courses which may assist them in enhancing the learning process. Research shows factors that will positively impact the relationship between teacher and students. Through convenience sampling technique total of 307 responses were collected through a close ended questionnaire from the students of virtual university in Karachi, Pakistan. Structural equation modeling (PLE-SEM) was used to evaluate the relation between the variables and co-relational design was used to find out the correlation between the 4 variables used in our study. The results of our study showed a positive and significant relation among all the variables, however, $p$ value of social presence and relationship satisfaction didn?t support the relation of both variables with each other.
\end{abstract}

Keywords: Teacher self-disclosure; social presence; social-penetration; MOOCs, Smart PLS Pakistan.

\section{Introduction}

Online education has shown a dramatic growth in the past decade. In the US, the overall population of higher education students in online enrollment growth rate (10 percent) has experienced further growth. According to Bowers and Kumar (2015), online learning has become an important part of our educational system and is not a new phenomenon anymore. Students are looking for convenience when to read, when to complete the assignments, and when to watch videos due to their busy lifestyles. Given the demands of lifestyle, it is no surprise that the online learning format's flexibility and convenience attracts students. Latest researches have also shown that the quality of online education is similar to face-to-face learning (Bowers \& Kumar, 2015). When we compare online classes to traditional (face to face) classroom settings, online classes provide many advantages to students such as flexibility, convenience and access to education.

\footnotetext{
*The Academy, Karachi. E-mail: komalkhan0331@hotmail.com

$\dagger$ Jinnah Sindh Medical University, Karachi. E-mail: tariq_rafi57@hotmail.com
} 
The topic of research in conventional (face - to - face) classroom settings has been teacher immediacy. Teacher immediacy, both verbal and non-verbal, focuses primarily on creating a close collaborative environment in which immediacy is defined as the relationship between the speaker and the objects he or she communicates about. Among various immediacy behaviors, comparatively little research examines the role of teacher self-disclosure (SD) in online learning environments. Students may have minimal knowledge about their teacher due to the nature of online environments that somehow limit non-verbal indications.

Teacher Self Disclosure is defined as the process by which a teacher allows students to know his or her inner being, thoughts, and emotions. Presently, insufficient attention has been paid to the role of Teacher Self Disclosure, particularly the effect of teacher selfdisclosure on the teacher student relationship, and how the teacher student relationship affects student-learning experiences in online classes (Song, Kim, \& Luo, 2016). Some researchers argue that feelings of isolation and disconnectedness in online courses are major reasons for high student drop-out rates in online courses. Compared to traditional face-toface courses, students' perceive a lack of social presence and interactions in online courses. Studies have found that students' sense of teacher's social presence in online courses influence their overall perceptions of learning and students who perceive a lack of social presence are more likely to withdraw and fail (Bowers \& Kumar, 2015).

Wei, Lihuan, Ling, and Yenchun (2018) defined the concept of social presence as an effective way to interact with a person through communication which helps to make strong interpersonal relationship between teacher and student. So and Brush (2008) explains their views on social presence that it's a model for analyzing the social and psychological dimension of a person, which helps to evaluate him before the communication. Social presence helps to judge the mindset of person in a better way which automatically helps during discussion or communication.

Wei et al. (2018) emphasized on the learning pattern in social presence because it helps to remember the things better and people are more engaging and learn things well. Therefore, it is necessary for the students to interact with their fellows as well and be real with them (Kris, Shuang, \& Tongmao, 2019). When it comes the learning outcomes and perceived learning in online education, past researchers such as, Marks, Sibley, and Arbaugh (2005) have concluded that online courses are very promising as facilitators are able to learn more about how to behave toward students taking online courses and how to lead the course content to improve perceived knowledge gain. Furthermore, Eom, Wen, and Ashill (2006) findings showed the importance of dialogue between student to student and teacher to student are predictors of perceived knowledge gain.

Massive open online courses (MOOCs) has been developed for the ease of both the students and teachers as it is the modern e-learning method which has attained acceptance in various universities and other educational institutes. Within the period of few years MOOC has become extremely popular and termed as being the modern classroom practice for teaching and learning. Spector, 2014 considers that MOOC has multiple benefits among which are user amount, openness and social interaction. On the basis of such benefits MOOC can be differentiated from other e-learning practices. While Hao (2016) determine that MOOCs important characteristic is the ability to connect massive amount of user or 
learners which can be accommodated even if they are distributed at number of locations. Secondly, the MOOC provides variation, the facilitators can make modifications in the course outline over the time even if the users are connected to the group. Whereas, in traditional classroom practice and other e-learning platforms do not provide such benefit due to which the practices and course content remains same for a longer period of time and makes it rigid (Liu, McKelroy, Kang, Harron, \& Liu, 2016).

In Pakistan, online education is picking up its pace slowly but steadily. Several local and national colleges/ universities such as, Allama Iqbal Open University, Virtual University, University of Peshawar, Comsats University and UET, have started offering online courses. Several public and private education sectors have also initiated online education with the introduction of information and communication technology (ICT) in Pakistan over the past few years. There are many educational steps taken by the Pakistani government, one of which is to initiate virtual classes in schools, colleges and universities. In 1974, a federal charter established the world's second Open University in Pakistan. One of Pakistan's largest universities, The Allama Iqbal Open University (AIOU) uses distance education programs to facilitate those students who are working outside. In the fields of mass education, female literacy, teacher education and media-based distance education, The AIOU has carried out pioneer work and to reach $65 \%$ of Pakistani students living in remote and rural areas, they are at present utilizing ICTs (Akhtar, Mehmood, Pervez, Aslam, \& Akhtar, 2016).

The objective of this research is to examine the impact of teacher self-disclosure and social presence on instructor- student relationship and perceived knowledge gain by students. How self-disclosure by teachers and their social presence satisfy the relationship between instructor and the learner and influence the perceived knowledge gain by students. This research will help the online education institutions of Pakistan to enhance the perceived learning and knowledge gain in online education and will provide them with the key variables that may help in enhancing the quality of online education.

\section{Literature Review}

\section{Theoretical Background}

Social penetration theory was given by Altman and Taylor (1973) that explained why relationships are formed and ended. It also means to develop a strong relationship among the individuals. When relation becomes stronger and close then you start to take part in each other's activity and understand each other. To explain how information exchange functions in the development and dissolution of interpersonal relationship social penetration theory was developed. Through self-disclosure, the process of purposefully revealing information about oneself the social penetration is accomplished (Rebecca, Alan, \& Matthew, 1993). Social penetration theory describes several layers inner layer which includes inner layer like spiritual values deep fears, secrets etc. Middle layer which include political and social attitude, superficial layer made of likes and dislikes, core personality includes most private information about a person. For social penetration there must be information exchange and peel back each other's layers through interpersonal interaction. When a person disclose 
something responder also disclose for equity (Carpenter \& Greene, 2015).

Pennington (2015) studied about building and maintaining relationships and exploring communication through social networking sites. They explain The Social Penetration Theory through the unique nature of online interpersonal interactions and self-disclosure. It also assesses social penetration theory in relation to communication online. The nature of self-disclosure changes as relationships develops Social penetration describes the process of bonding that moves a relationship from superficial to more intimate (Altman \& Taylor, 1973). The role of social presence of celebrities on lives of their follower's is individual characteristics are related to their celebrity following behavior. Loneliness of celebrity followers is positively associated with the frequent visits of the favorite celebrity social media the significant moderator which escalates the social presence of celebrity is more likely one-sided relationship perception with the celebrity (Kim, Kim, \& Yang, 2019). Jin, Sun, Wang, and Zhang (2017) gave social penetration theory with understanding of social presence and user engagement. The purpose of this study was to consider both technological and user factor and find out that both social presence and user engagement positively influence purchasing intention in virtual products. In online education students have less knowledge about their teachers due to the nature of online education that limit nonverbal cues (Dupin-Bryant, 2004).

\section{Hypotheses Development}

\section{Relationship Satisfaction Promotes Participation in MOOCs}

MOOCs can be platform for various students through which they can discuss and solve their queries with teachers specially those who are enrolled in online courses without any hesitations. Teacher's interaction with students no doubt enhances understanding level of students but on the other hand where numerous students who register for online courses also require such program. Which can contribute in knowledge sharing, improve selflearning procedure to execute knowledge or further advance in it such platform is provided by MOOC (Oded, Mor, \& Chen, 2009). It is determined that students who want to enhance their learning process and polish their skills prefer to be a part of online community. The understanding which they grasp through being part of e-learning system significantly progress their learning capabilities and identify the changes in personal development process. According to Li, Xu, and Sun (2015), the senior administration staff of universities and other educational institute students prefer to use MOOC comparative to traditional classroom practices as they consider that being part of MOOC they are getting benefit. If the students perceive that MOOC provides aid in the process of enhancing their skills so they are able to communicate better with their facilitators and participate often in MOOC program (Lewis, Agarwal, \& Sambamurthy, 2003).

$H_{1}$ : Relationship Satisfaction has a positive impact on Continuous Participation in MOOCs. 


\section{Relationship Satisfaction Improves the Perceived Knowledge Gain in Students}

A research conducted on predicting the student satisfaction (IV) and perceived learning (DV) in an online environment, the aim of the study was to find out that how the learnercontent interaction, learner instructor interaction and learner to learner interaction works for the student satisfaction which influence the learning outcomes of the students. The findings of the study show the importance to of learner to learner and teacher to learner interaction as well. It discussed that the peer to peer interaction helps in a positive way in order to improve the degree of satisfaction and positively affects the learning capacity of students. There are some limitations applied in the study i.e.; students were asked to report the self-efficacy and interaction, satisfaction and perceived learning as well (Bolliger \& Martin, 2018).

Mazer and Stowe (2015) examined a type of teacher self-disclosure which is teacher immediacy and its influence on student's learning outcomes. The findings suggested that high rather than low levels of teacher immediacy led to greater student motivation, affective learning and classroom climate. Teachers who use high amounts of immediacy led students to report the greatest affective learning. Positive teacher communication behaviors ultimately can decrease students' academic risk, lead to a more positive classroom experience, and promote a classroom environment where students' engagement and learning can flourish.

\section{$H_{2}$ : Relationship Satisfaction has a positive impact on Perceived Knowledge Gain.}

\section{Teacher Self-disclosure Improves the Satisfaction Level of Teacher-Student Re- lationship in the Online Education Environment}

Song et al. (2016) conducted a research on the role of self-disclosure by teachers and the relationship between teacher and students in computer-mediated learning in which the independent variable was teacher self- disclosure and teacher-student relationship was used as a dependent variable. The purpose of this research is to aware that how much it's important for a teacher to disclose himself though online communication with their student which helps them to maintain a strong and a healthy relationship with their students and students feel comfortable with their teacher which automatically enhance their capability to response through online learning system. The findings of this article suggest that teacher has to implement various strategies in order to enhance their relationship with a teacher and make learning environment more effective. Moreover, teacher has to ensure that his self-disclosure is perceived favorably which effects the student's comfort level and their learning experiences.

Karpouza and Emvalotis (2019) gave his research on the teacher student relationship in graduate education. The findings of the research shows general consensus among the participants that the university teacher is the one who, like a conductor, sets the tempo of the relationship - at least in the beginning. However, the role of the student is equally important for the development of the relationship. Collaborating together, e.g. working on a thesis, especially if the topic interests both the teacher and the student, facilitates deepening the teacher-student relationship. Moreover it creates respect and appreciation 
in mind of each other and the qualities of caring, understanding and trusting one another, being transparent, feeling equal, are developed.

$H_{3}$ : Social presence has a positive impact on relationship satisfaction.

$H_{4}$ : Teacher self-disclosure has a positive impact on relationship satisfaction.

\section{Teacher Self-Disclosure Positively Linked with Social Presence}

Borzea and Goodboy (2016) conducted a research on teacher's self-disclosure and students' engagement and interest to learn. The aim of this study is examine those relevant conditions in which a teacher disclose himself which influences the students learning and interest. Moreover, the study discussed that if the teacher disclose him and misbehave with the student so how it will influence towards their learning. Furthermore, there are some findings i.e.; if the teacher misbehave by disclosing himself so it will negatively influence the students engagement and their learning methods, teachers' relevant self-disclosure can be a reason through which a relationship can be weak and it effect the student learning, another suggestion is that the teacher has to keep their students engage during the lecture and it has to be clear, entertaining and delivered in a lively manner.

Similarly, the effects of instructor immediacy behaviors on participants' perception of the instructor's immediacy and social presence was examined (Schutt, Allen, \& Laumakis, 2009). Teacher immediacy was used as the dependent variable and perceived social presence was used as the independent variable. findings suggest that instructors who are able to monitor and project high-immediacy behaviors can reduce psychological distance in distance education settings and by doing so they can also increase social presence and students' perceptions of the instructors as caring, empathetic, emotionally expressive, and disclosing personality.

Richardson, Maeda, Lv, and Caskurlu (2017) analyzed the relation of social presence with knowledge gain and satisfaction in students in online education. The results indicated a strong significant relation between social presence and satisfaction in students and perceived knowledge gain by them. The meta-analysis on social presence revealed its exceedingly important function in predicting essential student outcomes, namely satisfaction and perceived learning.

$H_{5}$ : Teacher self-disclosure has a positive impact on social presence.

\section{Social Presence Mediates the Impact among the Teacher Self-Disclosure and Teacher-Student Relationship Satisfaction}

Sebastianelli, Swift, and Tamimi (2015a) discussed that a traditional (face to face) classroom environment makes it possible for students to interact with their teachers and fellow students in ways that are more interpersonal and social than in an online environment. Findings of the research on higher education generally show that the quality and quantity of interaction by students with the faculty and classmates, is a strong predictor of the academic success of student. Instructor - student interaction was used as the independent 
variable and perceived learning was used as the dependent variable. Instructor-student interaction, of course, encompasses more than providing feedback about academic progress and answering subject matter-related questions.

In the online environment, professors also interact with students in forums or chat rooms where faculty participation can help guide and encourage student discussion about course and non-course-related topics. Such interaction is considered critical for fostering in students a sense of connectedness and making them feel part of an online learning community (Sebastianelli, Swift, \& Tamimi, 2015b). It was discussed that professor- student interaction had a significant and positive influence on student satisfaction, suggesting that faculty who teach courses can enhance student satisfaction by taking an active role in facilitating discussions and by being responsive to students' questions and concerns. Ellahi (2018) conducted a research on the social websites as the learning environment in the business education. In high level of education and it's important to maintain a good relationship through online learning system which positively affects the performance and learning as well. The findings of this study includes many previous studies having a purpose to be aware about the results which shows the student satisfaction level in online learning environment by knowing the interaction level with the teachers and with the peers as well in order to shape students satisfaction in higher education.

$H_{6}$ : Social presence mediates the relationship between teacher self-disclosure and relationship satisfaction.

\section{Methodology}

\section{Research Model}

The conceptual model of present study is demonstrated in Figure 1. The model includes teacher self-disclosure, social presence, relationship satisfaction, perceived knowledge gain, and continuous participation in MOOCs platform. Moreover. Social presence is incorporated as a mediator between teacher self-disclosure and relationship satisfaction.

Figure 1

Conceptual Framework

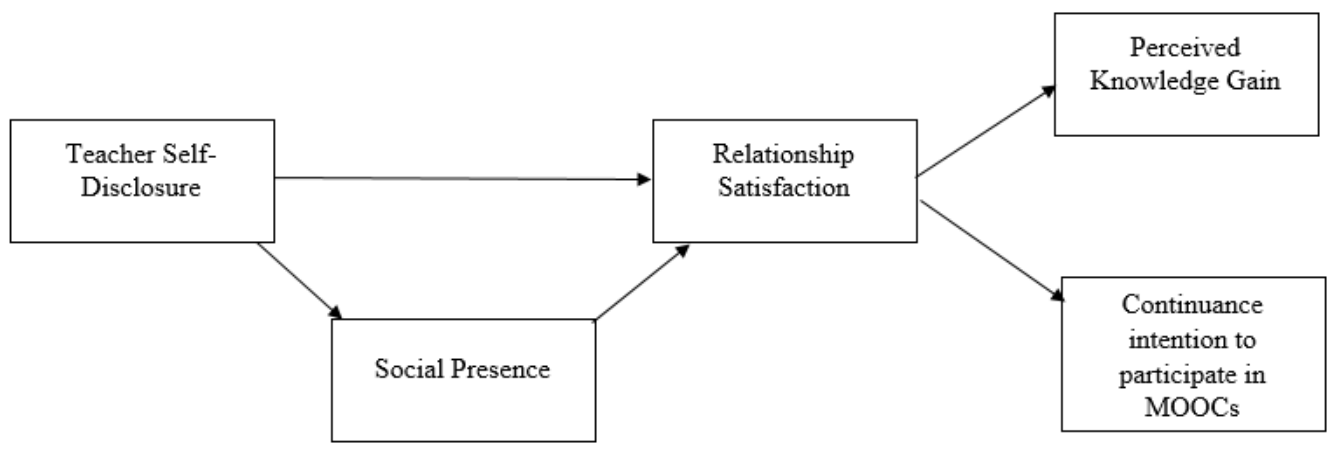




\section{Data Collection and Instrumentation}

In total, 326 respondents participated and after data screening 19 responses were deleted because of incomplete or missing values. The final sample size used in the study was 307. The sample size is based on reporting of many researchers who stated that three or more items per variable and a sample size of 100 is enough for convergence. According to Anderson and Gerbing (1984), the sample size of 150 is sufficient for a convergent and proper solution. For SEM technique, Churchill Jr (1979) reported that it can perform well even on the samples of 50-100. So, the sample size of our study is enough to perform estimations.

The data collection was performed by mean of questionnaire based on 5-point Likert scale from strongly disagree (1) to strongly agree (5). The survey questionnaire possessed a set of variables related to computer-mediated learning. Teacher self-disclosure was measured with 6 modified items from Cayanus and Martin (2008). With 6 items, modified from Vangelisti and Caughlin (1997), teacher-student relationship satisfaction was measured. Modified from Marks et al. (2005), perceived knowledge gain was measured with 4 items. Social presence was measured with 5 modified items from Biocca, Harms, and Burgoon (2003). Lastly, questions of continuous participation in MOOCs were adapted from (Shao, 2018). Responses were acquired on a 5-point Likert scale, going from $1=$ strongly disagree to $7=$ strongly agree

\section{Data Analysis}

Structural equation modeling (SEM) is a technique used to assess the theory's validity with the help of statistical facts (Ringle, Wende, \& Will, 2005; Raza, Umer, Qazi, \& Makhdoom, 2018). The two methods which are usually used are; (i) covariance based and (ii) variance based. The present study comprised of the variance based method i.e., Partial least square (PLS) is employed to evaluate the hypothetical model. The PLS-SEM is performed with the SmartPLS 3.2.9 software (Ringle, Wende, \& Becker, 2015; Ali, Raza, Qazi, \& Puah, 2018) and a bootstrap resampling of 5000 subsamples was used (Raza, Qazi, \& Umer, 2017). PLS (SEM) is considered suitable for several research situations (Raza, Qazi, \& Shah, 2018) and complicated models. The estimation was based on the guidelines of Anderson and Gerbing (1988) and done in two steps. In step one, the reliability and validity of the model have been assessed and in step two the assessment of structured model and hypotheses were tested.

\section{Demographics}

The details of demographic profiles are presented in Table 1. As seen from the demographic characteristics, that $51.80 \%$ respondents were Students. Entrepreneurs were $4.89 \%$ and $43.32 \%$ respondents were Employees. As for the gender, $57.65 \%$ respondents were male and $42.35 \%$ were females. In terms of age, $14.33 \%$ respondents come under the age group of $18-24$ years, $77.20 \%$ lie at the age bracket of $25-31$, and $8.47 \%$ belong to the age group of 33-39 years. 
Table 1

Demographic Profile

\begin{tabular}{lcc}
\hline Demographic items & Frequency & Percentage \\
\hline Age & & \\
$18-24$ & 44 & 14.33 \\
$25-31$ & 237 & 77.2 \\
$33-39$ & 26 & 8.47 \\
Gender & & \\
Male & 177 & 57.65 \\
Female & 130 & 42.35 \\
Occupation & & \\
Employee & 133 & 43.32 \\
Entrepreneur & 15 & 4.89 \\
Student & 159 & 51.8 \\
\hline
\end{tabular}

\section{Measurement Model}

The competency of the model is evaluated by the (i) construct reliability (ii) individual item reliability, (iii) convergent validity (iv) discriminant validity.

Table 2

Measurement Model Results

\begin{tabular}{|c|c|c|c|c|c|}
\hline & Items & Loadings & $\begin{array}{c}\text { Cronbach's } \\
\text { Alpha }\end{array}$ & $\begin{array}{l}\text { Composite } \\
\text { reliability }\end{array}$ & $\begin{array}{c}\text { Average variance } \\
\text { extracted }\end{array}$ \\
\hline & CP_MOOCs1 & 0.942 & & & \\
\hline \multirow{3}{*}{ CP_MOOCs } & CP_MOOCs2 & 0.979 & 0.947 & 0.963 & 0.897 \\
\hline & CP_MOOCs3 & 0.919 & & & \\
\hline & PKG1 & 0.787 & & & \\
\hline \multirow[t]{5}{*}{ PKG } & PKG2 & 0.827 & 0.812 & 0.875 & 0.637 \\
\hline & PKG3 & 0.772 & & & \\
\hline & PKG4 & 0.806 & & & \\
\hline & RS1 & 0.737 & & & \\
\hline & RS2 & 0.737 & & & \\
\hline \multirow[t]{5}{*}{ RS } & RS3 & 0.771 & 0.715 & 0.813 & 0.624 \\
\hline & RS4 & 0.754 & & & \\
\hline & RS5 & 0.7 & & & \\
\hline & SP1 & 0.871 & & & \\
\hline & SP2 & 0.871 & & & \\
\hline \multirow[t]{5}{*}{ SP } & SP3 & 0.859 & 0.905 & 0.93 & 0.726 \\
\hline & SP4 & 0.866 & & & \\
\hline & SP5 & 0.792 & & & \\
\hline & TSD1 & 0.822 & & & \\
\hline & TSD2 & 0.803 & & & \\
\hline \multirow[t]{3}{*}{ TSD } & TSD3 & 0.793 & 0.77 & 0.848 & 0.539 \\
\hline & TSD4 & 0.758 & & & \\
\hline & TSD5 & 0.841 & & & \\
\hline
\end{tabular}

As seen in table 2, all the variables have Cronbach's alpha and composite reliability, greater than 0.7 which meets the criteria of Straub (1989). The individual reliability of all the variables is greater than 0.7 which is in accordance with the criteria given by Churchill Jr (1979). According to him, each loading should be higher than 0.7 and the loadings. The loading above 0.7 confirms the instrument reliability. The convergent validity was evaluated through average variance extracted (AVE) and all variables have a minimum 
value of 0.50 which meets the benchmark proposed by Fornell and Larcker (1981).

The discriminant validity was assessed after the convergent validity by using (i) cross loading analysis (2) AVE. Table 3 represents the square root of AVE in the diagonal form and satisfy the criteria of Fornell and Larcker (1981) that AVE should be higher than the correlation between the variables. As seen from table 4 the individual items of each construct are loaded higher in their relevant constructs compare to the other constructs and the cross loading difference is also higher than the recommended criteria of 0.1 (Raza, Najmi, \& Shah, 2018). Thus, explains the discriminant validity adequacy. Furthermore, table 4 shows that the heterotrait-monotrait ratio of correlations (HTMT) shows that none of the HTMT criteria are higher than 0.85 (Raza, Umer, \& Shah, 2017).

Table 3

Fornell-Larcker criterion

\begin{tabular}{lccccc}
\hline & CP_MOOCs & PKG & RS & SP & TSD \\
\hline CP_MOOCs & 0.947 & & & & \\
PKG & 0.04 & 0.798 & & & \\
RS & 0.055 & 0.409 & 0.789 & & \\
SP & 0.023 & 0.747 & 0.324 & 0.852 & \\
TSD & -0.109 & 0.569 & 0.439 & 0.648 & 0.734 \\
\hline
\end{tabular}

Notes: $\mathrm{RS}=$ Relationship Satisfaction; CP_MOOCs= Continuance Gain; SP=Social Presence; TSD= Teacher Self-Disclosure. The diagonal elements (bold) represent the square root of AVE (average variance extracted).

Table 4

Loadings and Cross Loadings

\begin{tabular}{lccccc}
\hline & CP_MOOCs & PKG & RS & SP & TSD \\
\hline CP_MOOCs1 & 0.942 & 0.06 & 0.035 & 0.078 & -0.088 \\
CP_MOOCs2 & 0.979 & 0.053 & 0.071 & 0.024 & -0.083 \\
CP_MOOCs3 & 0.919 & -0.03 & 0.027 & -0.058 & -0.182 \\
PKG1 & 0.039 & 0.787 & 0.351 & 0.618 & 0.509 \\
PKG2 & 0.086 & 0.827 & 0.286 & 0.61 & 0.434 \\
PKG3 & 0.02 & 0.772 & 0.255 & 0.654 & 0.48 \\
PKG4 & -0.007 & 0.806 & 0.383 & 0.529 & 0.402 \\
RS1 & 0.067 & 0.345 & 0.737 & 0.231 & 0.288 \\
RS2 & 0.059 & 0.356 & 0.737 & 0.269 & 0.334 \\
RS3 & -0.073 & 0.268 & 0.771 & 0.162 & 0.274 \\
RS4 & 0.106 & 0.176 & 0.754 & 0.102 & 0.214 \\
RS5 & 0.034 & 0.209 & 0.7 & 0.297 & 0.366 \\
SP1 & 0.07 & 0.647 & 0.28 & 0.871 & 0.56 \\
SP2 & 0.019 & 0.641 & 0.278 & 0.871 & 0.536 \\
SP3 & 0.034 & 0.607 & 0.263 & 0.859 & 0.546 \\
SP4 & 0.002 & 0.662 & 0.297 & 0.866 & 0.595 \\
SP5 & -0.029 & 0.625 & 0.261 & 0.792 & 0.521 \\
TSD1 & -0.067 & 0.477 & 0.389 & 0.583 & 0.822 \\
TSD2 & -0.077 & 0.458 & 0.37 & 0.535 & 0.803 \\
TSD3 & -0.083 & 0.424 & 0.241 & 0.474 & 0.793 \\
TSD4 & -0.057 & 0.471 & 0.293 & 0.468 & 0.758 \\
TSD5 & -0.151 & 0.191 & 0.309 & 0.235 & 0.841 \\
\hline All self-loading is significant (bold). & & &
\end{tabular}


Table 5

Heterotrait-Monotrait Ratio (HTMT)

\begin{tabular}{lccccc}
\hline & CP_MOOCs & PKG & RS & SP & TSD \\
\hline CP_MOOCs & & & & & \\
PKG & 0.066 & & & & \\
RS & 0.117 & 0.505 & & & \\
SP & 0.064 & 0.787 & 0.385 & & \\
TSD & 0.158 & 0.711 & 0.59 & 0.761 & \\
\hline
\end{tabular}

Since, the measurement model confirms the convergent and discriminant validity thus, it confirms the variable distinctiveness and can be used to examine the structural model.

\section{Structural Model}

The structural model was analyzed by examining the standardized paths. Each path corresponds to a hypothesis. The results are shown in table 7. Six hypotheses were generated in the research.

Table 7

Result of Path Analysis

\begin{tabular}{ccccc}
\hline Hypothesis & Regression Path & Effect type & SRW & Remarks \\
\hline H1 & RS $\rightarrow$ CP_MOOCs & Direct Effect & $0.055^{*}$ & Supported \\
H2 & RS $\rightarrow$ PKG & Direct Effect & $0.420^{* * *}$ & Supported \\
H3 & SP $\rightarrow$ RS & Direct Effect & 0.066 & Not Supported \\
H4 & TSD $\rightarrow$ RS & Direct Effect & $0.403^{* * *}$ & Supported \\
H5 & TSD $\rightarrow$ SP & Direct Effect & $0.649^{* * *}$ & Supported \\
\hline Notes: SRW $=$ Standardized regression weight & & \\
$* * * \mathrm{p}<0.01,{ }^{* *} \mathrm{p}<0.05,{ }^{*} \mathrm{p}<0.10$ & & &
\end{tabular}

Table 8

Mediating Role of Social Presence

\begin{tabular}{|c|c|c|c|c|}
\hline Hypothesis & Regression Path & Effect type & SRW & Remarks \\
\hline $\mathrm{H} 6$ & $\mathrm{TSD} \rightarrow \mathrm{SP} \rightarrow \mathrm{RS}$ & Direct Effect & 0.41 & Not Supported \\
\hline
\end{tabular}

Figure 2

Conceptual Model

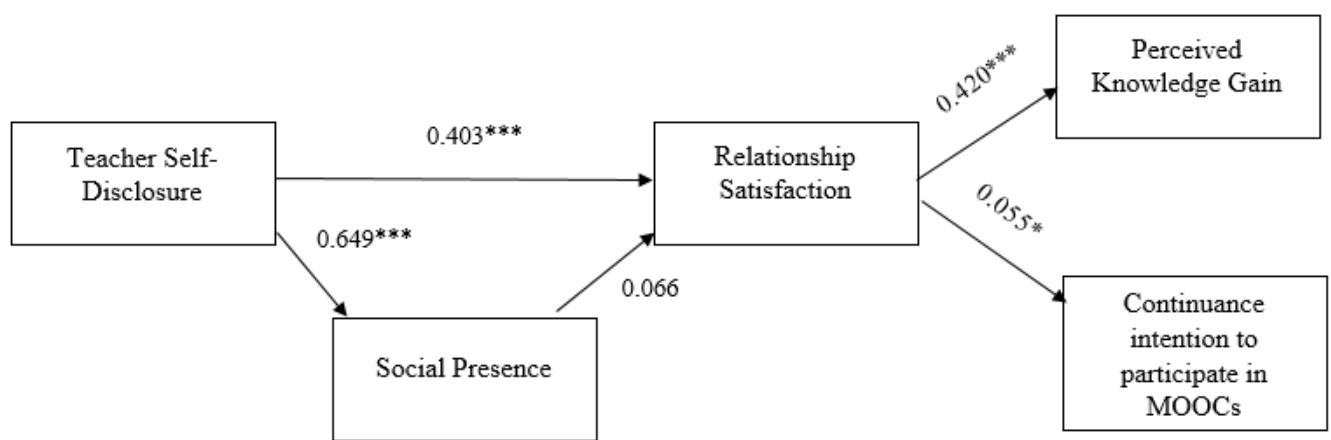




\section{Discussion}

The result of the regression analysis reported in table shows that in first hypothesis there is a positive relationship between student-teacher relationship satisfaction and continuous participation in MOOCs platform as $(\beta=0.055, \mathrm{p}<0.1)$. It shows that in virtual environment when students are satisfied so they depict positive attitude toward the continuous participation in massive online courses. Therefore, in the context of Pakistan students are willing to adopt online courses.

The result of the regression analysis reported in table shows that in first hypothesis there is a positive relationship between student-teacher relationship satisfaction and and perceived knowledge gain $(\beta=0.420, \mathrm{p}<0.01)$ and it is supported from the previous study. It means when the relationship is satisfied so it will beneficial for students to gain knowledge and for teachers to provide all the relevant information and resolve the queries as well. Also, Song et al. (2016) mentioned in their research that when Teacher Self disclosure helps build positive teacher student relationships, it can positively influence learning outcomes.

The result of third hypothesis suggested that there is a significant relationship between social presence and relationship satisfaction $(\beta=0.066, \mathrm{p}>0.01)$, however, the relation was not supported due to the p value. Wei et al. (2018) defined the concept of social presence as an effective way to interact with a person through communication which helps to make strong interpersonal relationship between teacher and student. He defined the concept of social presence as an effective way to interact with a person through communication which helps to make strong interpersonal relationship between teacher and student.

The result of the fourth hypothesis shows that there is a significant relationship between teacher self-disclosure and relationship satisfaction $(\beta=0.403, \mathrm{p}<0.01)$ and it is supported from the previous research of Park (2018) which proved that when a teacher reveals himself, the students feel a connection with them and hence, feel a level of satisfaction which automatically increases the teacher student relationship satisfaction level. Moreover, teachers and students may feel closer as a consequence of mutual self-disclosure. Instructor selfdisclosure is an inevitable facet of teaching social work practice that ultimately impacts the student-instructor relationship (Rasmussen \& Mishna, 2008).

The fifth hypothesis also shows a positive and significant relationship between teacher self-disclosure and social presence with $(\beta=0.649, \mathrm{p}<0.01)$ and it is supported from the previous study of Sung and Mayer (2012) who wrote that online teachers and learners must disclose their personal information as a means of building social relationships between teacher and learner. To do this, social participation increased over time through exchanging beliefs and values, sharing inspiration, and sharing work and professional interests. In distance learning, social interactions between teacher and learner, and between learners, can often be an exercise in frustration when students fell short of immediacy in online context responses compared to what might typically occur in a face-to-face structured classroom. Therefore, prescriptions for creating online social presence need to be developed in order to increase interaction between teachers and learners and between learners. Besides this, Aragon (2003) also supported that through teacher self-disclosure, social presence can be created. While establishing social presence for online environments, instructors play an important role. He said sharing personal stories and experiences makes social presence in 
online environments significantly easier, essentially in two ways. The first is to illustrate the credibility of the instructor. The second way is to share personal stories and experiences that allow the students to see that the teacher is a human being and that he has experience working in the same areas and fields in which the students aspire to work or may already be working.

The sixth hypothesis i.e. social presence mediate the relationship between teacher selfdisclosure and relationship satisfaction. It is not accepted as in direct effect the teacher selfdisclosure has a positive and significant impact on relationship satisfaction but in specific indirect effect it has an insignificant relation $(\beta=0.41, \mathrm{p}>0.1)$. It shows that working students, employees, and entrepreneur prefer online courses in this busy schedule because they cannot take admission in full-time institutes. Therefore, it is important for them to opt online courses that can boost their skills and help them professionally. Moreover, many students studying in colleges and universities also show positive attitude towards the online education. It shows that social presence does not mediate the relation. However, directly teacher self-disclosure is important.

\section{Conclusion and Recommendations}

\section{Conclusion}

The purpose behind the research was to examine the impact of teacher self-disclosure in online education and in social presence.in Karachi. A total of 307 responses were taken through a close ended questionnaire from the students of Virtual University, Karachi. Structural Equation Modeling (PLS-SEM) was used to evaluate the relation between the discussed variables. The approach used in this research for evaluation is quantitative, emphasizing the numerical analysis of data collection and helping the study support the research hypothesis. Furthermore, Co-relational design was used to find out the relationship between the variables and convenience sampling technique was chosen to gather data from the students who had the experience of learning academic or career-oriented courses through web based learning system. The result of the first hypothesis shows that there is a positive and significant relation between teacher-self disclosure and Social presence. Result of the second hypothesis shows that there is a positive and significant impact between relationship satisfaction and perceived knowledge. Result of the third hypothesis shows a positive but insignificant impact of social presence on relationship satisfaction. The result of the fourth and last hypothesis shows that there is a positive and significant relationship between teacher self-disclosure and social presence. Each result has been supported with the previous studies/researches.

\section{Managerial Implications}

According to the results it is recommended to universities and higher education commission to promote the culture of online education as there are only few universities in Pakistan who are implementing the system of online education and in our research we have targeted specifically a private university named Virtual University who are one of those few 
institutions implementing the system of online education. Also, the management not to compromise on the safety of the personal information the people or the target people who have submitted or filled the questionnaire's there personal information should be only used for the purpose of research only by doing that thing the trust of the target people would be on the safer side. Moreover, the management/policy makers in online education to promote student to student and teacher to student discussion programs and arrange social events, workshops, counselling sessions where the students and teachers can get to know each other's experiences and stories.

\section{Future Recommendations}

Present research was based on few but vital factors effecting the learning in online education. However, if we expand our view and observe the online education system more closely we would definitely have other factors effecting the web based learning system as well. Hence, the future researchers should discover more variables related to online education and study their effects in computer mediated learning. One limitation our research faced was in the collection of data. We could only collect data from students in Karachi and therefore, we recommended that the students in other cities of Pakistan should also be included in the data collection. In addition to this, the sample size of our research was 307 and so, future researchers can take a larger sample size than this to evaluate these variables. Moreover, a different tool; e.g. focus group, interview, open ended surveys, etc. can also be utilized to gather the data from the chosen sample size. 


\section{References}

Akhtar, N., Mehmood, M. T., Pervez, M. Z., Aslam, F., \& Akhtar, H. M. A. (2016). Factors influencing the perception of customers in Islamic banking: A case study in Pakistan. International Review of Management and Business Research, 5(3), 844. doi: 10.18639/merj.2016.02.200914

Ali, M., Raza, S. A., Qazi, W., \& Puah, C.-H. (2018). Assessing e-learning system in higher education institutes. Interactive Technology and Smart Education, 15(1), 59-78.

Altman, I., \& Taylor, D. A. (1973). Social penetration: The development of interpersonal relationships. Holt, Rinehart \& Winston.

Anderson, J. C., \& Gerbing, D. W. (1984). The effect of sampling error on convergence, improper solutions, and goodness-of-fit indices for maximum likelihood confirmatory factor analysis. Psychometrika, 49(2), 155-173.

Anderson, J. C., \& Gerbing, D. W. (1988). Structural equation modeling in practice: A review and recommended two-step approach. Psychological Bulletin, 103(3), 411.

Aragon, S. R. (2003). Creating social presence in online environments. New Directions for Adult and Continuing Education, 2003(100), 57-68.

Biocca, F., Harms, C., \& Burgoon, J. K. (2003). Toward a more robust theory and measure of social presence: Review and suggested criteria. Presence: Teleoperators \& Virtual Environments, 12(5), 456-480.

Bolliger, D. U., \& Martin, F. (2018, sep). Instructor and student perceptions of online student engagement strategies. Distance Education, 39(4), 568-583.

Borzea, D., \& Goodboy, A. K. (2016). When instructors self-disclose but misbehave: Conditional effects on student engagement and interest. Communication Studies, $67(5), 548-566$.

Bowers, J., \& Kumar, P. (2015). Students' perceptions of teaching and social presence: A comparative analysis of face-to-face and online learning environments. International Journal of Web-Based Learning and Teaching Technologies, 10(1), 27-44.

Carpenter, A., \& Greene, K. (2015). Social penetration theory. The International Encyclopedia of Interpersonal Communication, 1-4.

Cayanus, J. L., \& Martin, M. M. (2008). Teacher self-disclosure: Amount, relevance, and negativity. Communication Quarterly, 56(3), 325-341.

Churchill Jr, G. A. (1979). A paradigm for developing better measures of marketing constructs. Journal of Marketing Research, 16(1), 64-73.

Dupin-Bryant, P. A. (2004). Pre-entry variables related to retention in online distance education. The American Journal of Distance Education, 18(4), 199-206.

Ellahi, A. (2018). Social networking sites as formal learning environments in business education. Journal of Educational Technology \& Society, 21(4), 64-75.

Eom, S. B., Wen, H. J., \& Ashill, N. (2006). The determinants of students' perceived learning outcomes and satisfaction in university online education: An empirical investigation. Decision Sciences Journal of Innovative Education, 4(2), 215-235.

Fornell, C., \& Larcker, D. F. (1981). Evaluating structural equation models with unobservable variables and measurement error. Journal of Marketing Research, 18(1), 39-50. 
Hao, Y. (2016). The development of pre-service teachers' knowledge: A contemplative approach. Computers in Human Behavior, 60, 155-164.

Jin, W., Sun, Y., Wang, N., \& Zhang, X. (2017). Why users purchase virtual products in MMORPG? An integrative perspective of social presence and user engagement. Internet Research, 27(2), 408-427.

Karpouza, E., \& Emvalotis, A. (2019). Exploring the teacher-student relationship in graduate education: A constructivist grounded theory. Teaching in Higher Education, $24(2), 121-140$.

Kim, J., Kim, J., \& Yang, H. (2019). Loneliness and the use of social media to follow celebrities: A moderating role of social presence. The Social Science Journal, 56(1), $21-29$.

Kris, M. Y. L., Shuang, G., \& Tongmao, L. (2019). Student enrollment, motivation and learning performance in a blended learning environment: The mediating effects of social, teaching, and cognitive presence. Computers \& Education, 136, 1-12.

Lewis, W., Agarwal, R., \& Sambamurthy, V. (2003). Sources of influence on beliefs about information technology use: An empirical study of knowledge workers. MIS Quarterly, 27(4), 657-678.

Li, M., Xu, S., \& Sun, M. (2015). Analysis of learning behaviors in MOOCs- a case study of the course "principles of electric circuits". Open Education Research, 21 (2), 63-69.

Liu, M., McKelroy, E., Kang, J., Harron, J., \& Liu, S. (2016). Examining the use of facebook and twitter as an additional social space in a MOOC. American Journal of Distance Education, 30(1), 14-26.

Marks, R. B., Sibley, S. D., \& Arbaugh, J. B. (2005). A structural equation model of predictors for effective online learning. Journal of Management Education, 29(4), $531-563$.

Mazer, J. P., \& Stowe, S. A. (2015). Can teacher immediacy reduce the impact of verbal aggressiveness? Examining effects on student outcomes and perceptions of teacher credibility. Western Journal of Communication, 80(1), 21-37.

Oded, N., Mor, N., \& Chen, Y. (2009). Analysis of participation in an online photo-sharing community: A multidimensional perspective. Journal of the American Society for Information Science and Technology, n/a-n/a. Retrieved from https://doi.org/ 10.1002\%2Fasi.21278 doi: 10.1002/asi.21278

Pennington, N. (2015). Building and maintaining relationships in the digital age: Using social penetration theory to explore communication through social networking sites (Unpublished doctoral dissertation).

Rasmussen, B. M., \& Mishna, F. (2008). A fine balance: Instructor self-disclosure in the classroom. Journal of Teaching in Social Work, 28(1-2), 191-207.

Raza, S. A., Najmi, A., \& Shah, N. (2018). Transferring knowledge from universities to organizations by business students. Journal of Workplace Learning, 29(4), 531-563.

Raza, S. A., Qazi, W., \& Shah, N. (2018). Factors affecting the motivation and intention to become an entrepreneur among business university students. International Journal of Knowledge and Learning, 12(3), 221-241.

Raza, S. A., Qazi, W., \& Umer, A. (2017). Facebook is a source of social capital building among university students: Evidence from a developing country. Journal of Educa- 
tional Computing Research, 55(3), 295-322.

Raza, S. A., Umer, A., Qazi, W., \& Makhdoom, M. (2018). The effects of attitudinal, normative, and control beliefs on m-learning adoption among the students of higher education in Pakistan. Journal of Educational Computing Research, 56 (4), 563-588.

Raza, S. A., Umer, A., \& Shah, N. (2017). New determinants of ease of use and perceived usefulness for mobile banking adoption. International Journal of Electronic Customer Relationship Management, 11(1), 44-65.

Rebecca, B. R., Alan, M. R., \& Matthew, M. M. (1993). The role of self-disclosure and selfawareness in affinity-seeking competence. Communication Research Reports, 10(2), $115-127$.

Richardson, J. C., Maeda, Y., Lv, J., \& Caskurlu, S. (2017). Social presence in relation to students' satisfaction and learning in the online environment: A meta-analysis. Computers in Human Behavior, 71, 402-417.

Ringle, C. M., Wende, S., \& Becker, J.-M. (2015). Smartpls 3. Boenningstedt: SmartPLS $\mathrm{GmbH}$.

Ringle, C. M., Wende, S., \& Will, A. (2005). Smartpls 2.0. M3. Hamburg: SmartPLS. Retrieved from http://www. smartpls. com.

Schutt, M., Allen, B. S., \& Laumakis, M. A. (2009). The effects of instructor immediacy behaviors in online learning environments. Quarterly Review of Distance Education, $10(2), 135-148$.

Sebastianelli, R., Swift, C., \& Tamimi, N. (2015a). Factors affecting perceived learning, satisfaction, and quality in the online MBA: A structural equation modeling approach. Journal of Education for Business, 90(6), 296-305.

Sebastianelli, R., Swift, C., \& Tamimi, N. (2015b). Factors affecting perceived learning, satisfaction, and quality in the online MBA: A structural equation modeling approach. Journal of Education for Business, 90(6), 296-305.

So, H.-J., \& Brush, T. A. (2008). Student perceptions of collaborative learning, social presence and satisfaction in a blended learning environment: Relationships and critical factors. Computers \& Education, 51(1), 318-336.

Song, H., Kim, J., \& Luo, W. (2016). Teacher-student relationship in online classes: A role of teacher self-disclosure. Computers in Human Behavior, 54, 436-443.

Straub, D. W. (1989). Validating instruments in MIS research. MIS Quarterly, 147-169.

Sung, E., \& Mayer, R. E. (2012). Five facets of social presence in online distance education. Computers in Human Behavior, 28(5), 1738-1747.

Vangelisti, A. L., \& Caughlin, J. P. (1997). Revealing family secrets: The influence of topic, function, and relationships. Journal of Social and Personal Relationships, $14(5), 679-705$.

Wei, W., Lihuan, G., Ling, H., \& Yenchun, J. W. (2018). Effects of social-interactive engagement on the dropout ratio in online learning: insights from MOOC. Behaviour E Information Technology, 38(6), 621-636. 